\title{
Cost-Effective Single Switch Multi-Channel LED Driver
}

\author{
Sang-Soo Hwang ${ }^{*}$, Won-Sun Hwang ${ }^{*}$, and Sang-Kyoo Han ${ }^{\dagger}$ \\ ${ }^{*}$ Department of Electronic Engineering, Kookmin University, Seoul, Korea
}

\begin{abstract}
In this paper, a cost-effective single switch multi-channel LED (light emitting diode) driver is proposed. While conventional LED drivers require as many non-isolated DC/DC converters as the number of LED channels, the proposed LED driver needs only one power switch and several balancing capacitors instead of expensive non-isolated DC/DC converters. Therefore, the proposed driver features a simpler structure, with a lower cost and a higher efficiency. Because its power switch can be turned off under the zero current switching condition, it has very desirable advantages such as improved electromagnetic interference characteristics and high efficiency. Moreover, it uses only a small number of DC blocking capacitors with no additional active devices for the current balancing of multi-channel LEDs. As a result, the proposed driver exhibits high reliability and is cost effective. To confirm the validity of the proposed driver, a theoretical analysis is performed, and design considerations and experimental results obtained from a prototype that is applicable to a 46" LED-TV are presented.
\end{abstract}

Key words: Current balancing, Multi-channel LED driver

\section{INTRODUCTION}

Recently, LCD (liquid crystal display) flat panel displays have become one of the fastest growing products in large screen displays due to various advantages such as their low power consumption, long lifespan, low profile, and high contrast ratio [1]-[2]. Because LCDs are non-emissive display devices, they usually require a BLU (back light unit) in monitor and TV applications. For conventional LCD TVs, a CCFL (cold cathode fluorescent lamp) is usually used as a BLU. However, restrictions on the use of mercury $(\mathrm{Hg})$ as specified by the RoHS (Restriction of Hazardous Substances) directive, requires that environmentally friendly lamps must be employed as backlight sources. Moreover, it is very difficult to implement low profile and high definition TVs.

LEDs (light emitting diodes) are now considered to be more suitable for BLUs and other lighting applications. Although the high cost and low luminous efficiency of LEDs make it difficult for them to be widely adopted as a backlight source, LEDs can satisfy the RoHS directive. They also

Manuscript received Sep. 15, 2014; accepted Oct. 26, 2014

Recommended for publication by Associate Editor Yan Xing.

${ }^{\dagger}$ Corresponding Author: djhan@kookmin.ac.kr

Tel: +82-910-5075, Fax: +82-910-4449, Kookmin University

*Dept. of Electronic Engineering, Kookmin University, Korea possess many desirable merits such as long lifespan, wide color gamut, and fast response. Moreover, since the luminous efficiency and production cost of LEDs have been improved, they have become among the most suitable solution for BLUs.

To realize sufficient luminance for large-sized LCD TVs, series-parallel configured multi-channel LEDs are usually adopted. In driving multi-channel LEDs, it is very important to obtain uniform and sufficient luminance despite the characteristic variations of each LED. However, because each LED has different properties depending on the voltage, current and temperature, there may be LED current variations even at the same driving voltage depending on the temperature of the $p-n$ junction, the time variation and the differences in the characteristics of each array [3]-[5]. Therefore, individual LED arrays should not be individually placed in parallel, and should be driven by a constant current source instead of a constant voltage. Further, a single LED driver is generally used for each LED array to maintain a constant and balanced current through each of the multichannel LED arrays, where a non-isolated boost converter is usually used as the LED driver.

In the meantime, the power supplies for LED TVs are generally required to produce $12.8 \mathrm{~V}$ for the audio amplifier, digital signal processing and auxiliary circuit. Additionally, they should also regulate the LED currents. However, most 


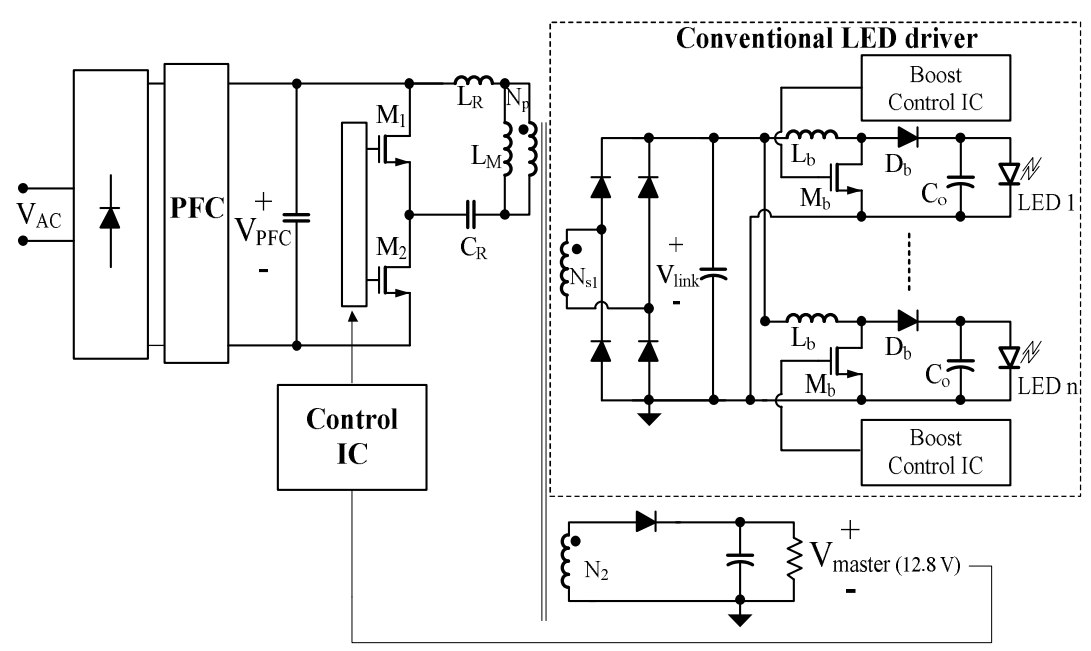

Fig. 1. Schematic of the conventional LED driver.

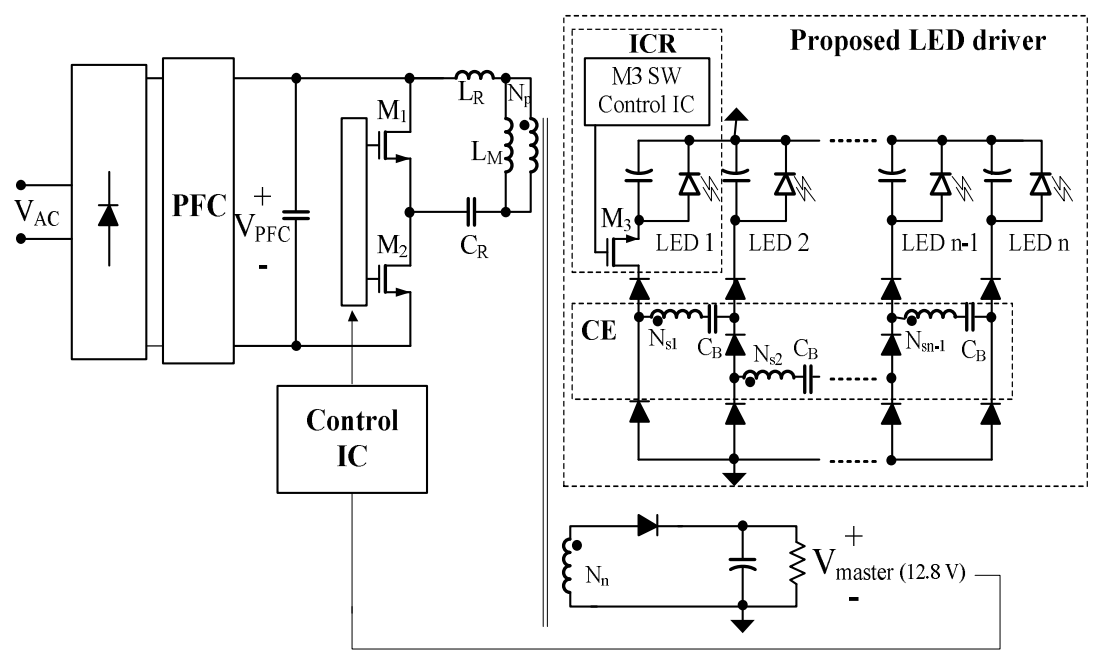

Fig. 2. Schematic of the proposed LED driver.

converters cannot obtain independently and tightly regulated dual outputs such as voltages or currents by themselves. Therefore, in recently developed LED TVs, one master output is tightly regulated by the main controller and the other slave outputs are regulated by an SSPR (secondary side post regulator) such as an extra non-isolated DC/DC converter, where the SSPR can also be implemented by the abovementioned non-isolated boost converter to balance the current in the multi-channel LED driver [6]-[7]. However, because the SSPR is composed of an inductor, capacitor, diode, switch, and control IC, it has several drawbacks such as a high production cost, cumbersome nature, and poor efficiency, due to its cascaded configuration.

To overcome all of the drawbacks faced by previous approaches, a new cost-effective single switch multi-channel LED driver is proposed in this paper. The overall power supply for an LED TV employing the proposed LED driver is constructed using a dual output LLC resonant converter, where the master output produces a tightly regulated $12.8 \mathrm{~V}$ voltage and the slave output supplies the input voltage of the proposed LED driver. The proposed LED driver then regulates all of the LED currents so that they are kept constant and balanced. The proposed driver is composed of only one power switch and several balancing capacitors without extra SSPRs. Therefore, it has a lower cost, simpler structure, higher efficiency, and higher power density.

\section{CONVEnTIONAL LED DRIVER}

Fig. 1 shows a schematic of a conventional LED driver for an n-channel LED TV. As shown in this figure, the overall system consists of three cascaded power conversion stages, namely a PFC (power factor corrector), an isolated DC/DC converter, and an LED driver. The PFC stage produces a constant DC link voltage from an AC input voltage source. Then, the isolated DC/DC converter converts this link voltage into the tightly regulated DC voltage $(12.8 \mathrm{~V})$ for auxiliary circuits and the unregulated DC voltage for the LED driver, where the LLC resonant converter is usually adopted as an isolated DC/DC converter due to its favorable advantages such as high efficiency and low EMI [8]-[9]. Then, to drive multi-channel LED arrays from the unregulated DC voltage, 


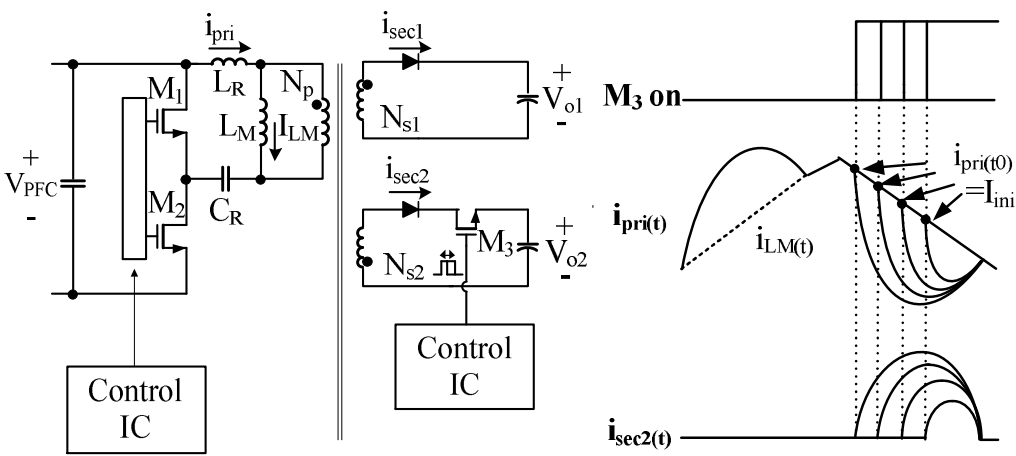

Fig. 3. Dual output LLC resonant converter with proposed ICR and its operational principles

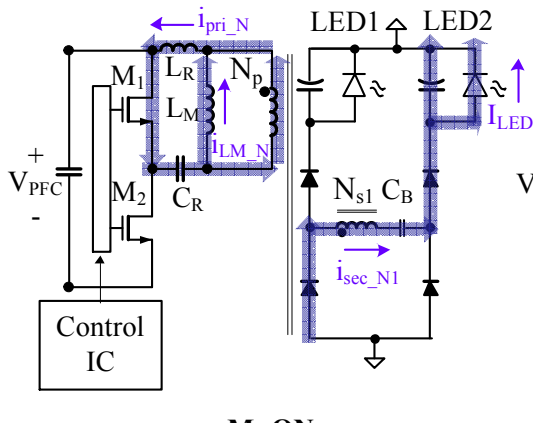

$\mathrm{M}_{1} \mathrm{ON}$

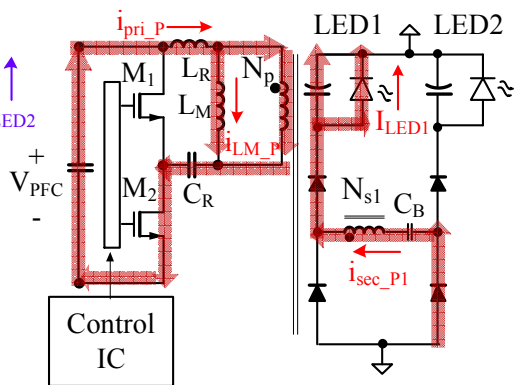

$\mathrm{M}_{2} \mathrm{ON}$

Fig. 4. Current equalizer circuit and operation principles.

conventional LED drivers require one boost converter per LED channel to control the current through each LED. Although these boost converters can tightly control all of the LED currents, they have several disadvantages such as their high production cost, low power conversion efficiency, and cumbersome nature. Moreover, many of the active devices and driver ICs used in boost converters can deteriorate the system reliability.

\section{PROPOSED LED DRIVER}

Fig. 2 shows an example of the proposed n-channel LED driver. The proposed LED driver can tightly control one channel of LED current using only one switch. At the same time, other channel LED currents can be automatically balanced with each other by using DC blocking capacitors. Therefore, the proposed driver requires a small number of devices and has a low production cost. Moreover, because an overall power converter employing the proposed LED driver consists of two cascaded power conversion stages, its circuit structure and energy conversion efficiency are simpler and higher than those of conventional drivers. In addition, because its power switch can be turned off under the ZCS (zero current switching) condition, it has very desirable advantages such as improved EMI characteristics and heat generation.

As shown in Figure 2, the proposed LED driver consists of an ICR (initial current-control regulator) and a CE (current equalizer). The ICR controls only one channel of LED current, and the other channel LED currents are balanced with each other by the CE. Therefore, all of the LED currents can be controlled and balanced. The detailed operational principles are described as follows.

\section{A. Initial Current-Control Regulator}

Fig. 3 shows an example of a dual output LLC resonant converter, and it illustrates the operational principles of the proposed ICR. One output voltage $\mathrm{V}_{\mathrm{o} 1}$ of the dual output LLC converter is controlled by varying the switching frequency, as in the case of a conventional single output LLC resonant converter, where $\mathrm{V}_{\mathrm{o} 1}$ and $\mathrm{V}_{\mathrm{o} 2}$ correspond to the master $12.8 \mathrm{~V}$ and slave driving voltages for one of the multi-channel LEDs, respectively. On the other hand, the other output voltage $\mathrm{V}_{02}$ can be regulated by varying the initial current $I_{\text {ini. The }}$ primary current $i_{\text {pri(t) }}$ and the output voltage $V_{02}$ of the LLC resonant converter can be expressed as follows:

$$
\begin{aligned}
i_{p r i}(t)= & I_{\text {ini }} \cos \left(\omega\left(t-t_{0}\right)\right)+\frac{V_{I N}-V_{c r . i n i}-V_{o} / n}{\sqrt{L_{R} / C_{R}}} \sin \left(\omega\left(t-t_{0}\right)\right) \\
V_{o 2}= & \frac{R_{o 2}}{n_{2} T_{s}} \int_{0}^{t_{r}-D^{\prime} T_{s}}\left[I_{\text {ini }} \cos w t+\frac{V_{c r . i n i 2}-V_{I N}+V_{o 2} / n_{2}}{\sqrt{L_{R} / C_{R}}} \sin w t\right. \\
& \left.-\left\{\frac{V_{o 2}}{n_{2} L_{m}} t-\left(\left(n_{2} I_{o 2}-n_{1} I_{o 1}\right)+\frac{V_{o 1} T_{s}}{4 n_{1} L_{m}}\right)\right\}\right] d t
\end{aligned}
$$

Equations (1) and (2) show that the output voltage $\mathrm{V}_{\mathrm{o} 2}$ depends on $\mathrm{I}_{\mathrm{ini}}$. As a result, it can be regulated by varying the initial current $\mathrm{I}_{\text {ini. }}$. In other words, because a larger $\mathrm{I}_{\text {ini }}$ 


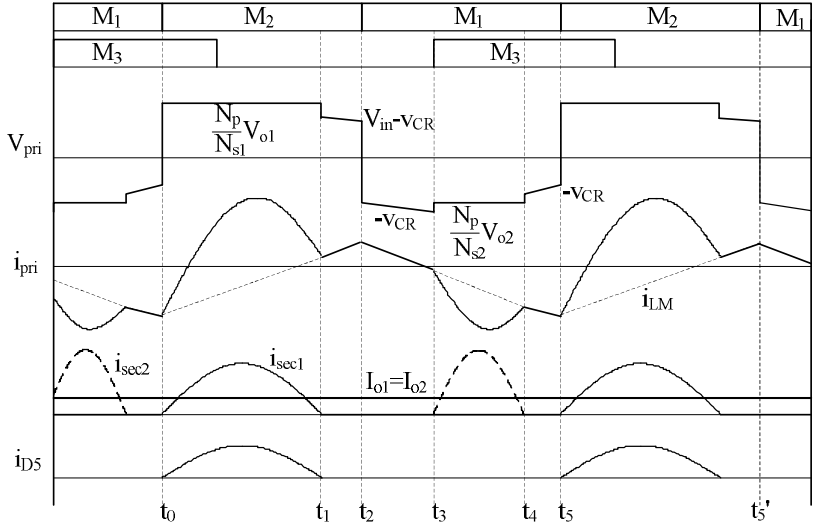

Fig. 5. Key waveforms of the proposed converter.

produces a larger resonant primary current $i_{\text {pri(t) }}$, a larger secondary current $\mathrm{i}_{\sec 2(t)}=\mathrm{i}_{\text {pri(t) }}-\mathrm{i}_{\mathrm{LM}(\mathrm{t})}$ is transferred to the output side. As a consequence, a larger output voltage can be achieved. Therefore, the output voltage $\mathrm{V}_{\mathrm{o} 2}$ can be regulated by controlling the initial current $\mathrm{I}_{\text {ini }}$ of $\mathrm{i}_{\text {pri(t) }}$. Based on these operational principles, one master output voltage of the dual output LLC converter can be controlled by the switching frequency modulation and the other slave output voltage can be controlled by the initial current $\mathrm{I}_{\mathrm{ini}}$ as shown in Fig. 3 .

\section{B. Current Equalizer}

Fig. 4 shows the proposed CE for a multi-channel LED with the exception of the abovementioned ICR. For the sake of simplicity, a 2-channel LED driver is used as an example. As seen in the figure, the proposed $\mathrm{CE}$ is composed of 1 transformer, 1 capacitor, 4 diodes and drive 2-channel LED arrays. The current balancing principles of the proposed $\mathrm{CE}$ are described as follows. When the switch $\mathrm{M}_{2}$ is on and the switch $M_{1}$ is off during one half of the switching period of the driver, the current through the transformer's primary side is the same as $i_{\text {pri }}$. Therefore, all of the transformer secondary side currents are identical as follows:

$$
n \cdot<i_{p r i_{-} P}-i_{L M_{-} P}>=<i_{\text {sec }_{-} P 1}>=I_{L E D 1}
$$

where $<\bullet>$ is the average value of “๑”, and $n$ is the transformer turn ratio.

When $M_{1}$ is on and $M_{2}$ is off during the other half of the switching period of the driver, the current through the transformer primary side is also the same as $\mathrm{i}_{\text {pri } \mathrm{N}}$. Therefore, all of the transformer secondary side currents are identical as follows:

$$
n \cdot<i_{p r i_{-} N}-i_{L M M_{-} N}>=<i_{\text {sec_N1 }}>=I_{L E D 2}
$$

At this point, because the blocking capacitor $\left(C_{B}\right)$ is serially connected to the transformer's secondary side, the DC offset current of the transformer's secondary side can be eliminated. In other words, the average currents through the transformer's secondary side during each half of the switching period are equal to one another as follows:

$$
<i_{\text {se__P1 }}>=<i_{\text {sec_N1 }}>
$$

Finally, from equations (3), (4) and (5), all of the LED currents can be perfectly balanced as follows:

$$
I_{L E D 1}=I_{L E D 2}
$$

Accordingly, the proposed driver can keep the currents through all of the LED arrays constant and balanced using only passive devices such as transformers and capacitors. Moreover, if only the current through one LED array is controlled, all of the currents can be controlled by the abovementioned principles. Therefore, the proposed LED driver can control the current through the LED channel using the ICR. At the same time, it can equalize all of the LED currents using the CE.

\section{OPERATING PRINCIPLES OF PROPOSED LED DRIVER}

The key waveforms of the proposed converter are presented in Fig. 5, and its operation modes in five modes according to the conduction state of each switch are shown in Figure 6. For the convenience of the mode analysis in the steady state, the following assumptions are made:

1) The switches $\left(M_{1}-M_{3}\right)$ are ideal except for their internal diodes.

2) The transformer is ideal except for its magnetizing inductance $\mathrm{L}_{M}$ and leakage inductance $\mathrm{L}_{\mathrm{R}}$.

3) The output capacitors $\mathrm{C}_{\mathrm{o} 1}$ and $\mathrm{C}_{\mathrm{o} 2}$ are large enough to be considered as the constant $\mathrm{DC}$ voltage sources $\mathrm{V}_{\mathrm{o} 1}$ and $\mathrm{V}_{\mathrm{o} 2}$, respectively.

4) The switching transition interval between $M_{1}$ and $\mathrm{M}_{2}$ is small enough to be ignored.

Before $t_{0}$, it is assumed that the switch $M_{1}$ is initially conducting, and a transformer magnetizing current $i_{\text {LM }}$ flows through $\mathrm{M}_{1}$, as shown in Fig. 6(a).

Mode 1 [ $\left.t_{0}-t_{1}\right]$ : When $\mathrm{M}_{1}$ is turned off and $\mathrm{M}_{2}$ is on at $\mathrm{t}_{0}$, mode 1 begins, as shown in Fig. 6(b). Because the voltage $\mathrm{V}_{\mathrm{IN}}-\mathrm{V}_{\mathrm{CR}}$ is applied to the transformer primary side, the dot of the transformer is positive. As a result, $\mathrm{D}_{2}, \mathrm{D}_{4}$, and $\mathrm{D}_{5}$ are conducting. Therefore, $i_{\text {pri }}$ flows due to the resonance between $\mathrm{C}_{\mathrm{R}}$ and $\mathrm{L}_{\mathrm{R}}$. Because the reflected output voltage $\left(\mathrm{N}_{\mathrm{P}} / \mathrm{N}_{\mathrm{S} 2}\right) \mathrm{V}_{\text {master }}$ is applied to $\mathrm{L}_{\mathrm{M}}$, the magnetizing current $\mathrm{i}_{\mathrm{LM}}$ increases linearly.

Mode 2 [ $\left.t_{1}-t_{2}\right]$ : When the transformer primary current $i_{\text {pri }}$ becomes equal to $i_{\text {LM }}$ and $i_{\text {sec } 1}$, and $i_{D 5}$ reach zero at $t_{1}$, mode 2 begins, as shown in Figure 6(c). At this moment, because all of the rectifier diodes are blocked and $\mathrm{V}_{\mathrm{IN}}-\mathrm{V}_{\mathrm{CR}}$ is applied to $\mathrm{L}_{\mathrm{M}}+\mathrm{L}_{\mathrm{R}}, \mathrm{i}_{\text {pri }}$ is still increasing because of the resonance between $\mathrm{C}_{\mathrm{R}}$ and $\mathrm{L}_{\mathrm{M}}+\mathrm{L}_{\mathrm{R}}$. However, because the resonant frequency between $C_{R}$ and $L_{M}+L_{R}$ is very low when compared with the switching frequency, $\mathrm{i}_{\text {pri }}$ can be assumed to have increased linearly.

Mode 3 [ $t_{2}-t_{3}$ ]: When $\mathrm{M}_{2}$ is turned off and $\mathrm{M}_{1}$ is on at $\mathrm{t}_{2}$, mode 3 begins, as shown in Fig. 6(d). Although $M_{1}$ is conducting and $-\mathrm{V}_{\mathrm{CR}}$ is applied to the transformer primary 


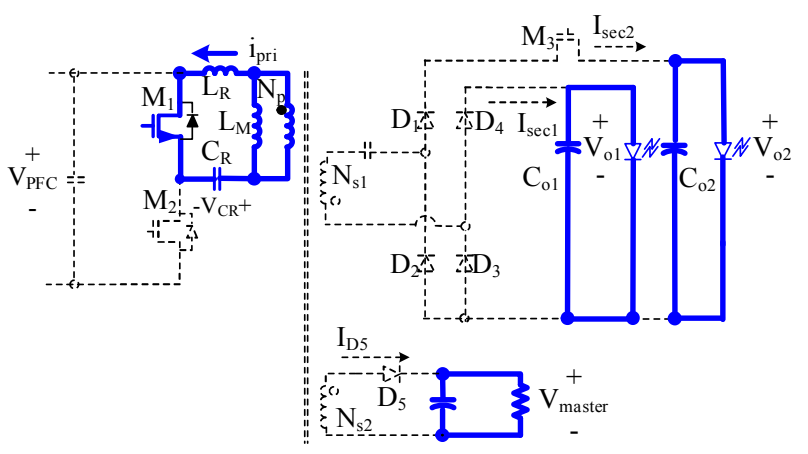

(a)

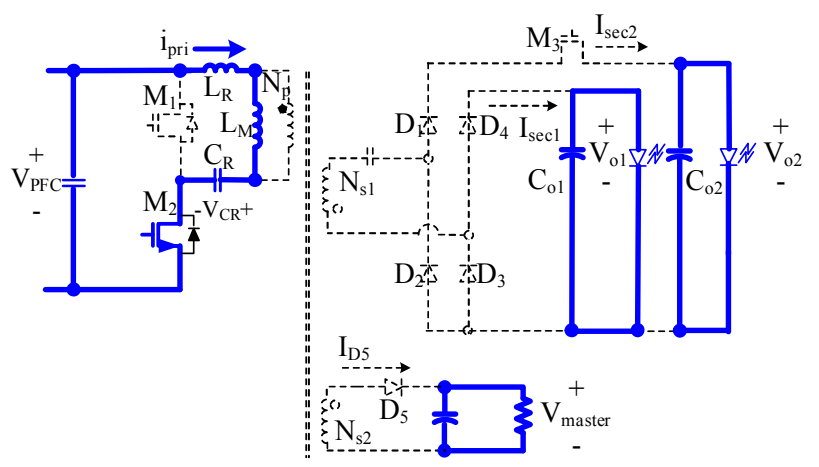

(c)

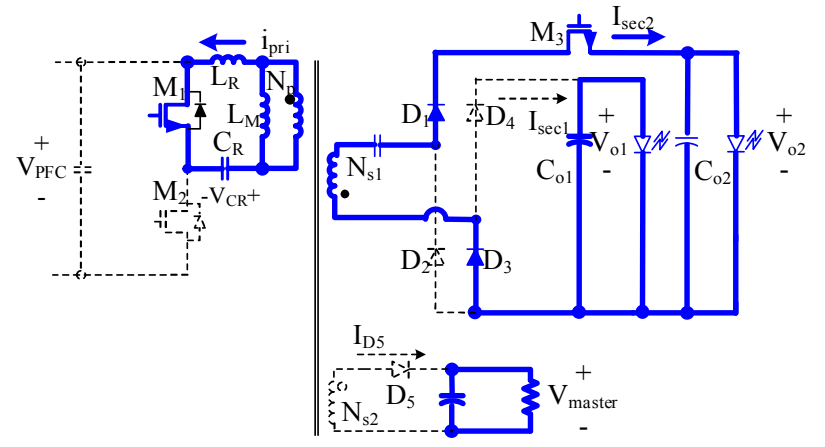

(e)

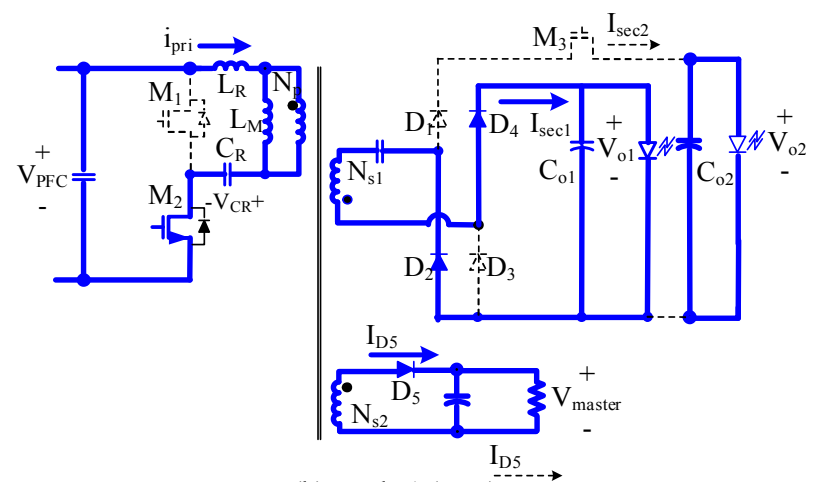

(b)
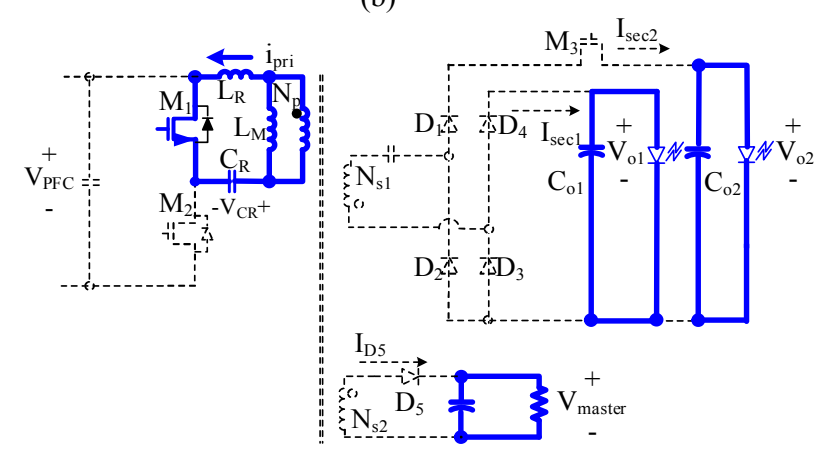

(d)
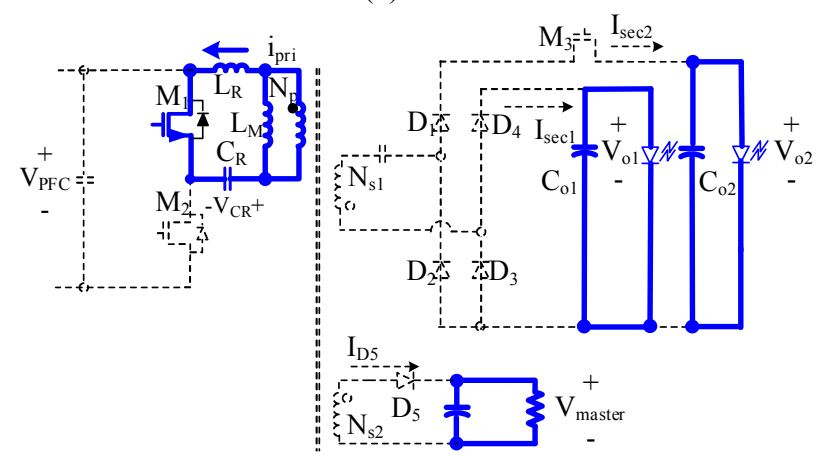

(f)

Fig. 6. Operation modes of the proposed converter. (a) Mode $0\left(\sim t_{0}\right)$. (b) Mode $1\left(t_{0} \sim t_{1}\right)$. (c) Mode $2\left(t_{1} \sim t_{2}\right)$. (d) Mode 3 ( $\left.t_{2} \sim t_{3}\right)$. (e) Mode $4\left(\mathrm{t}_{3} \sim \mathrm{t}_{4}\right)$. (f) Mode $5\left(\mathrm{t}_{4} \sim \mathrm{t}_{5}\right)$.

side, the turned-off $\mathrm{M}_{3}$ prevents the input power from being transferred to the output side. Therefore, there is no resonance between $C_{R}$ and $L_{R}, i_{\text {sec2 } 2}$ is maintained at zero, and the initial current $\mathrm{I}_{\text {ini }}$ decreases with a slope of $-\mathrm{V}_{\mathrm{CR}} /\left(\mathrm{L}_{\mathrm{R}}+\mathrm{L}_{\mathrm{M}}\right)$. As shown in Figure $5, \mathrm{i}_{\text {pri }}$ decreases by the resonance between $C_{R}$ and $\mathrm{L}_{\mathrm{M}}+\mathrm{L}_{\mathrm{R}}$. Similarly, because the resonant frequency between $\mathrm{C}_{\mathrm{R}}$ and $\mathrm{L}_{\mathrm{M}}+\mathrm{L}_{\mathrm{R}}$ is very low, $\mathrm{i}_{\text {pri }}$ can be assumed to have decreased linearly.

Mode 4 [ $\left.t_{3}-t_{4}\right]$ : When $\mathrm{M}_{3}$ is turned on at $t_{3}$, mode 4 begins, as shown in Figure 6(e). When $\mathrm{M}_{3}$ is turned on with $\mathrm{M}_{1}$ conducting, $D_{1}$ and $D_{3}$ are turned on. At the same time, the resonant current between $C_{R}$ and $L_{R}$ is transferred to the output side. Moreover, because the reflected output voltage $\left(\mathrm{N}_{\mathrm{p}} / \mathrm{N}_{\mathrm{s} 2}\right) \mathrm{V}_{\text {master }}$ is applied to $\mathrm{L}_{\mathrm{M}}, \mathrm{i}_{\mathrm{LM}}$ decreases linearly.

Mode 5 [ $\boldsymbol{t}_{4}-\boldsymbol{t}_{5}$ ]: When $\mathrm{i}_{\text {pri }}$ becomes equal to $\mathrm{i}_{\mathrm{LM}}$, and $\mathrm{i}_{\mathrm{sec} 2}$ reaches zero at $t_{4}$, mode 5 begins, as shown in Figure 6(f). At this time, because all of the rectifier diodes are blocked and $\mathrm{V}_{\mathrm{CR}}$ is applied to $\mathrm{L}_{\mathrm{M}}+\mathrm{L}_{\mathrm{R}}$, $\mathrm{i}_{\text {pri }}$ is still decreasing due to the resonance between $C_{R}$ and $L_{M}+L_{R}$. In particular, if only $M_{3}$ is turned off between $t_{4}$ and $t_{5}{ }^{\prime}, M_{3}$ can be turned off under zero current switching. When $M_{1}$ is turned off at $t_{5}$, mode 5 ends. Subsequently, the operation from $t_{0}$ to $t_{5}$ is repeated.

\section{ANALYSIS OF THE PROPOSED LED DRIVER}

For the convenience of the analysis, it is assumed that the dead time between $M_{1}$ and $M_{2}$ is zero, and that $i_{L M}$ increases or decreases linearly with a slope of $\mathrm{V}_{\mathrm{o} 1} / \mathrm{n}_{1} \mathrm{~L}_{\mathrm{M}}$ or $-\mathrm{V}_{\mathrm{o} 2} / \mathrm{n}_{2} \mathrm{~L}_{\mathrm{M}}$, respectively, where $\mathrm{V}_{\mathrm{o} 1}$ and $\mathrm{V}_{\mathrm{o} 2}$ correspond to the master 12.8 $\mathrm{V}$ and slave driving voltages, respectively, for one of the multi-channel LEDs.

As shown in Fig. 7, the steady-state offset current $\left\langle\mathrm{i}_{\mathrm{LM}}>\right.$ 


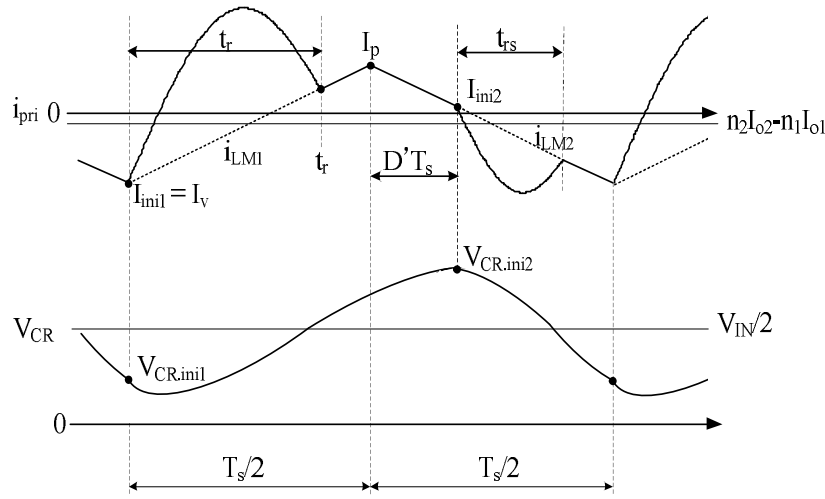

Fig. 7. Transformer primary current $i_{\text {pri }}$ and resonant capacitor voltage $\mathrm{V}_{\mathrm{CR}}$.

through $\mathrm{L}_{\mathrm{M}}$ can be obtained as:

$$
\left\langle i_{L M}\right\rangle=n_{2} I_{o 2}-n_{1} I_{o 1}
$$

where $\mathrm{n}_{1}=\mathrm{N}_{\mathrm{s} 1} / \mathrm{N}_{\mathrm{p}}$ and $\mathrm{n}_{2}=\mathrm{N}_{\mathrm{s} 2} / \mathrm{N}_{\mathrm{p}}$.

From equation (7), the values of $I_{p}$ and $I_{v}$ can be expressed as follows:

$$
\begin{gathered}
I_{p}=\left(n_{2} I_{o 2}-n_{1} I_{o 1}\right)+\frac{V_{o 1} T_{s}}{4 n_{1} L_{M}} \\
I_{v}=\left(n_{2} I_{o 2}-n_{1} I_{o 1}\right)-\frac{V_{o 2} T_{s}}{4 n_{2} L_{M}}
\end{gathered}
$$

where $\mathrm{T}_{\mathrm{S}}$ is the switching period.

Moreover, $\mathrm{i}_{\mathrm{LM} 1}$ and $\mathrm{i}_{\mathrm{LM} 2}$ can be obtained from equations (8) and (9) as follows:

$$
\begin{aligned}
& i_{L M 1}(t)=\frac{V_{o 1}}{n_{1} L_{M}} t+\left(\left(n_{2} I_{o 2}-n_{1} I_{o 1}\right)-\frac{V_{o 2} T_{s}}{4 n_{2} L_{M}}\right) \\
& i_{L M 2}(t)=-\frac{V_{o 2}}{n_{2} L_{M}} t+\left(\left(n_{2} I_{o 2}-n_{1} I_{o 1}\right)+\frac{V_{o 1} T_{s}}{4 n_{1} L_{M}}\right)
\end{aligned}
$$

Meanwhile, when $\mathrm{M}_{2}$ is conducting, the difference between $i_{\text {pri }}$ and $i_{\text {LM1 }}$ is transferred to the output side as $i_{\text {sec1 }}$. Similarly, when $M_{1}$ is conducting, the difference between $i_{\text {pri }}$ and $i_{\text {LM2 }}$ is transferred to the output side as $i_{\text {sec2 }}$. From equations (7), (10), and (11), $i_{\sec 1}$ and $i_{\sec 2}$ can be obtained as follows:

$$
\begin{aligned}
i_{\mathrm{sec} 1}=\left|i_{p r i}-i_{L M 1}\right|= & I_{\text {ini } 1} \cos \omega t+\frac{V_{c r . i n i 1}-V_{I N}+V_{o 1} / n_{1}}{\sqrt{L_{R} / C_{R}}} \sin \omega t \\
& -\left\{\frac{V_{o 1}}{n_{1} L_{m}} t+\left(\left(n_{2} I_{o 2}-n_{1} I_{o 1}\right)-\frac{V_{o 2} T_{s}}{4 n_{2} L_{m}}\right)\right\} \\
i_{\mathrm{sec} 2}=\left|i_{p r i}-i_{L M 2}\right|= & I_{\text {ini } 2} \cos \omega t+\frac{V_{c r . i n i 2}-V_{I N}+V_{o 2} / n_{2}}{\sqrt{L_{R} / C_{R}}} \sin \omega t \\
& -\left\{\frac{V_{o 2}}{n_{2} L_{m}} t-\left(\left(n_{2} I_{o 2}-n_{1} I_{o 1}\right)+\frac{V_{o 1} T_{s}}{4 n_{1} L_{m}}\right)\right\}
\end{aligned}
$$

where $\omega$ is the angular frequency.

Therefore, the output load currents $\mathrm{I}_{01}$ and $\mathrm{I}_{02}$ can be calculated from the mean values of $i_{\sec 1}$ and $i_{\text {sec } 2}$, respectively, as follows:
TABLE I

DESIGN SPECIFICATIONS AND CIRCUIT PARAMETERS

\begin{tabular}{l|l}
\hline \multicolumn{1}{c|}{ Items } & \multicolumn{1}{c}{ Values } \\
\hline \hline Input voltage, $\mathrm{V}_{\mathrm{AC}}$ & $90 \sim 264 \mathrm{~V}_{\mathrm{rms}}$ \\
\hline PFC output voltage, $\mathrm{V}_{\mathrm{PFC}}$ & $390 \mathrm{~V}$ \\
\hline Master output voltage, $\mathrm{V}_{\text {master }}$ & $12.8 \mathrm{~V}$ \\
\hline Rated voltage and current of LED & $180 \mathrm{~V} / 250 \mathrm{~mA}$ \\
\hline Magnetizing inductor of transformer, $\mathrm{L}_{\mathrm{m}}$ & $350 \mu \mathrm{H}$ \\
\hline Leakage inductor of transformer, $\mathrm{L}_{\mathrm{R}}$ & $70 \mu \mathrm{H}$ \\
\hline Resonant capacitor, $\mathrm{C}_{\mathrm{R}}$ & $18 \mathrm{nF}$ \\
\hline Switching frequency, $\mathrm{f}_{\mathrm{sw}}$ & $115 \sim 130 \mathrm{kHz}$ \\
\hline DC blocking capacitor, $\mathrm{C}_{\mathrm{B}}$ & $22 \mathrm{nF}$ \\
\hline LED and Master output capacitors, $\mathrm{C}_{\mathrm{LED}} / \mathrm{C}_{\mathrm{o}}$ & $33 \mu \mathrm{F} 1 \mathrm{EA} / 390 \mu \mathrm{F}$ \\
& $2 \mathrm{EA}$ \\
\hline
\end{tabular}

$$
\begin{aligned}
I_{o 1}= & \frac{1}{n_{1} T_{s}} \int_{0}^{t_{r}}\left[I_{i n i 1} \cos \omega t+\frac{V_{c r . i n i 1}-V_{I N}+V_{o 1} / n_{1}}{\sqrt{L_{R} / C_{R}}} \sin \omega t\right. \\
& \left.-\left\{\frac{V_{o 1}}{n_{1} L_{m}} t+\left(\left(n_{2} I_{o 2}-n_{1} I_{o 1}\right)-\frac{V_{o 2} T_{s}}{4 n_{2} L_{m}}\right)\right\}\right] d t=\frac{V_{o 1}}{R_{o 1}} \\
I_{o 2}= & \frac{1}{n_{2} T_{s}} \int_{0}^{t_{r}-D^{\prime} T_{s}}\left[I_{i n i 2} \cos \omega t+\frac{V_{c r . i n i 2}-V_{I N}+V_{o 2} / n_{2}}{\sqrt{L_{R} / C_{R}}} \sin \omega t\right. \\
& \left.-\left\{\frac{V_{o 2}}{n_{2} L_{m}} t-\left(\left(n_{2} I_{o 2}-n_{1} I_{o 1}\right)+\frac{V_{o 1} T_{s}}{4 n_{1} L_{m}}\right)\right\}\right] d t=\frac{V_{o 2}}{R_{o 2}}
\end{aligned}
$$

where D' is the turn-off duty ratio of the switch $\mathrm{M}_{3}$.

From equations (14) and (15), the output voltages $\mathrm{V}_{\mathrm{o} 1}$ and $\mathrm{V}_{\mathrm{o} 2}$ can be obtained as follows:

$$
\begin{gathered}
V_{o 1}=\frac{\gamma\left(V_{c r . i n i 1}-V_{I N}\right) \cdot\left(\cos \omega t_{r}-1\right)}{\left(\frac{n_{1} T_{s}}{R_{o 1}}-\frac{\alpha}{\omega} \sin \omega t_{r}-\frac{\gamma}{n_{1}}\right) \cdot\left(\cos \omega t_{r}-1\right)+\frac{t_{r}{ }^{2}}{2 n_{1} L_{M}}+\alpha t_{r}} \\
V_{o 2}=\frac{\gamma\left(V_{c r . i n i 2}-V_{I N}\right) \cdot\left(\cos \omega t_{r s}-1\right)}{\left(\frac{n_{2} T_{s}}{R_{o 2}}-\frac{\beta}{\omega} \sin \omega t_{r s}-\frac{\gamma}{n_{2}}\right) \cdot\left(\cos \omega t_{r s}-1\right)+\frac{t_{r s}{ }^{2}}{2 n_{2} L_{M}}+\beta t_{r s}}
\end{gathered}
$$

where $\mathrm{t}_{\mathrm{rs}}=\mathrm{t}_{\mathrm{r}}-\mathrm{D}^{\prime} \mathrm{T}_{\mathrm{s}}$ and:

$$
\begin{aligned}
& \alpha=-\left(\frac{n_{1}^{2} R_{o 2}-n_{2}{ }^{2} R_{o 1}}{n_{1} R_{o 1} R_{o 2}}+\frac{T_{s}}{4 n_{1} L_{M}}\right), \beta=\left(\frac{n_{1}^{2} R_{o 2}-n_{2}{ }^{2} R_{o 1}}{n_{2} R_{o 1} R_{o 2}}+\frac{\left(4 D^{\prime}-1\right) T_{s}}{4 n_{2} L_{M}}\right) \\
& \gamma=\frac{1}{\omega} \sqrt{\frac{C_{R}}{L_{R}}}
\end{aligned}
$$

If it is assumed that the equivalent circuit of the LED is a serially connected equivalent resistor $R_{\text {eq }}$ and a forward voltage drop $\mathrm{V}_{\mathrm{F}}$, the current through the LED can be expressed as follows:

$$
I_{L E D}=\frac{V_{o 2}-V_{F}}{\mathrm{R}_{\mathrm{e} q}}
$$

\section{EXPERIMENTAL RESULTS}

To confirm the validity of the proposed LED driver, a prototype for a 46" 2-channel LED TV is constructed. Table I shows the design specifications and circuit parameters. 


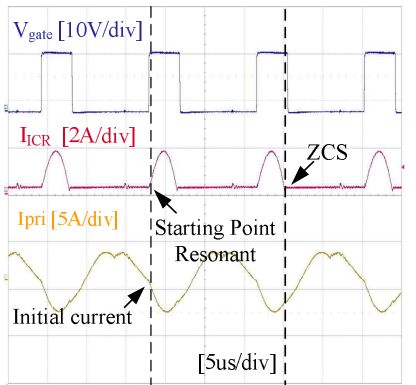

(a)

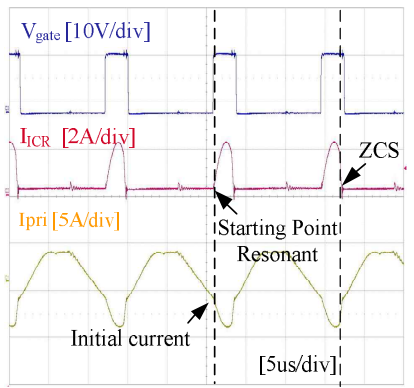

(b)
Fig. 8. Key waveforms according to master load conditions. (a) No load. (b) Full load.

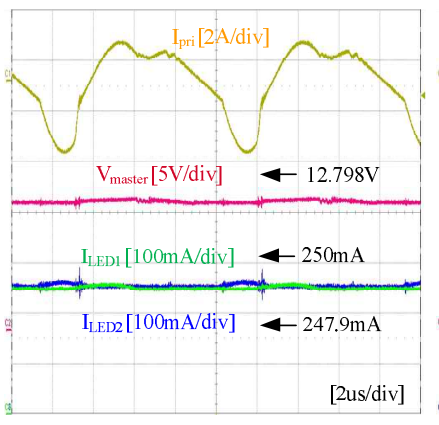

(a)

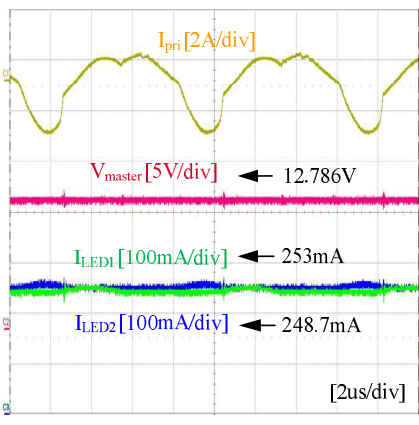

(b)
Fig. 9. LED currents and master voltage according to master load conditions. (a) No load. (b) Full load.

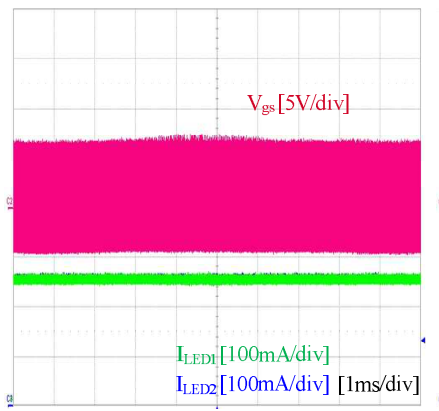

(a)

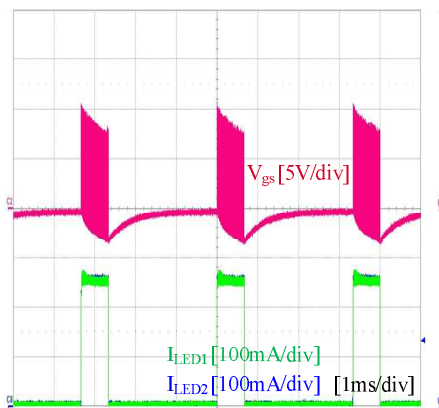

(c)

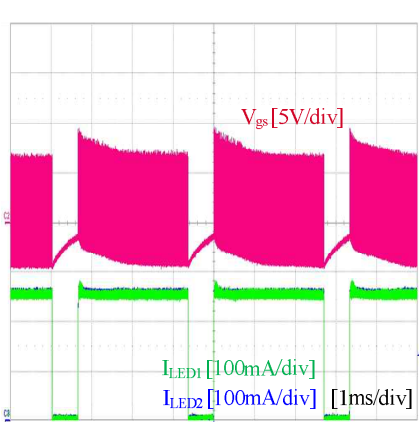

(b)

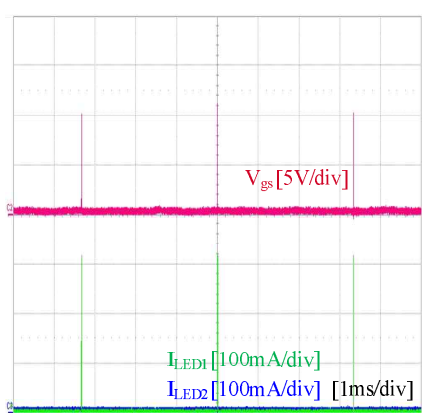

(d)
Fig. 10. LED currents and M3 gate signal according to dimming conditions. (a) $100 \%$ Dimming. (b) $80 \%$ Dimming. (c) $20 \%$ Dimming. (d) $0.2 \%$ Dimming.

Fig. 8 shows the key waveforms according to the master load conditions. As shown in this figure, the switching frequencies at no-load and full-load are measured as $130 \mathrm{kHz}$ and $115 \mathrm{kHz}$, respectively, to regulate the master output

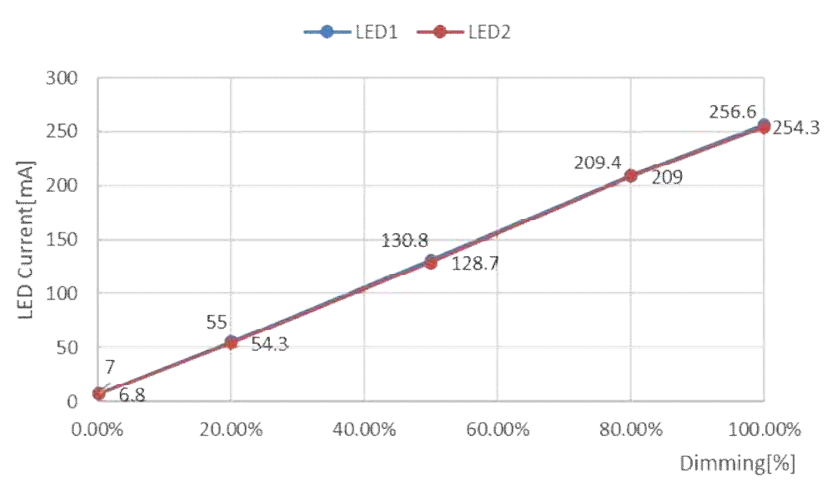

Fig. 11. LED currents according to dimming conditions.

TABLE II

COMPARISONS BETWEEN CONVENTIONAL AND PROPOSED 2CHANNEL LED DRIVERS WITH RESPECT TO THE NUMBER OF DEVICES

\begin{tabular}{|c|c|c|c|}
\hline \multicolumn{2}{|c|}{ Items } & $\begin{array}{l}\text { Conventional } \\
\text { LED driver }\end{array}$ & $\begin{array}{l}\text { Proposed } \\
\text { LED driver }\end{array}$ \\
\hline \multicolumn{2}{|c|}{ Transformer } & 1EA (EE3414) & 1EA (EE3414) \\
\hline \multirow{2}{*}{$\begin{array}{l}\text { Power } \\
\text { switch }\end{array}$} & $\mathrm{M}_{1} \& \mathrm{M}_{2}$ & $\begin{array}{c}\text { 2EA } \\
\text { (STD14NM50N) }\end{array}$ & $\begin{array}{c}\text { 2EA } \\
\text { (STD14NM50N) }\end{array}$ \\
\hline & $\mathrm{M}_{3}$ & 2EA (AOD5N40) & 1EA (AOD5N40) \\
\hline \multirow{2}{*}{ Diode } & $\mathrm{D}_{1} \sim \mathrm{D}_{4}$ & 4EA(SF36G) & 4EA(SF36G) \\
\hline & $\mathrm{D}_{\mathrm{b}}$ & 2EA (MUR460) & 0EA \\
\hline \multicolumn{2}{|c|}{ Link capacitor } & $1 \mathrm{EA}(47 \mu \mathrm{F} / 200 \mathrm{~V})$ & 0EA \\
\hline \multicolumn{2}{|c|}{ Inductor } & $2 \mathrm{EA}(220 \mu \mathrm{H})$ & 0EA \\
\hline \multirow[b]{2}{*}{ Control IC } & LLC & 1EA (SEM3110) & 1EA (SEM3110) \\
\hline & SSPR / ICR & $\begin{array}{l}\text { 1EA (SLC5012M- } \\
\text { 20pin) }\end{array}$ & $\begin{array}{c}\text { 1EA (UCC3583- } \\
\text { 14pin) }\end{array}$ \\
\hline
\end{tabular}

voltage. Under this situation of frequency variation, the ICR can tightly regulate the LED current by varying the initial current. Moreover, because $\mathrm{M}_{3}$ is turned off after $\mathrm{i}_{\mathrm{sec} 2}$ reaches $0 \mathrm{~A}$, the $\mathrm{ZCS}$ of $\mathrm{M}_{3}$ can be ensured along the entire load range. Fig. 9 shows both the LED current and master output voltage according to the master output load conditions. As shown in this figure, the proposed LED driver has excellent performance with respect to master voltage regulation, LED current regulation, and current balancing regardless of the master load conditions. Further, Figure 10 shows the LED currents and $\mathrm{M}_{3}$ gate signal of the proposed LED driver according to various dimming conditions. In addition, figure 11 shows that the current through each of the LED channels can be well controlled and balanced along the entire dimming range. Table II shows comparisons between the conventional and proposed LED drivers with respect to the number of devices. As shown in this table, because the proposed LED driver does not need an extra boost converter for current control and balancing, the proposed LED driver has fewer devices than the conventional driver. Therefore, the proposed LED driver features a simpler structure and a higher power density than the conventional driver. Moreover, the efficiency 
of the proposed LED driver is measured to be about $86 \%$, which is higher than the $84 \%$ obtained by the conventional driver at $\mathrm{V}_{\mathrm{ac}}=220 \mathrm{~V}_{\mathrm{rms}}$. In this case, the PFC is the same and the efficiency is about $97 \%$. This is because the boost converter stage is removed in the proposed LED driver.

\section{CONCLUSIONS}

In this paper, a cost-effective single switch multi-channel LED driver is proposed. While the conventional LED driver requires as many boost converters as the number of LED channels, the proposed driver needs only one power switch and several balancing capacitors. In addition, it features a lower cost, simpler structure, higher efficiency, and higher power density. Meanwhile, because an overall system employing a conventional LED driver is composed of 3 power conversion stages, its power conversion efficiency is measured as $84 \%$ at $\mathrm{V}_{\mathrm{ac}}=220 \mathrm{~V}_{\mathrm{rms}}$. On the other hand, because an overall system employing the proposed LED driver consists of only 2 power conversion stages and the ICR switch can be turned off under the ZCS condition, its overall power conversion efficiency is measured to be as high as $86 \%$ at $\mathrm{V}_{\mathrm{ac}}=220 \mathrm{~V}_{\mathrm{rms}}$. Moreover, although the proposed driver is composed of only passive devices for current balancing, its $\mathrm{CE}$ can achieve excellent current balancing performance with a maximum of $1.7 \%$ deviation. Due to these advantages, the proposed LED driver is expected to be suitable for various LED applications such as displays and lighting.

\section{ACKNOWLEDGMENT}

This research (Grants No. C0212217) was supported by the research program 2013 of Kookmin university and Business for Cooperative R\&D between Industry, Academy, and Research Institute funded Korea Small and Medium Business Administration in 2014.

\section{REFERENCES}

[1] L. Y. Pan, S. C. Chang, M. Y. Liao, and Y. T Lin, "The future development of global LCD TV industry," in Proc. PICMET, pp. 1818-1821, Aug. 2007.

[2] F. Xiaoyun, L. Xiaojian, and W. Yan, "Research and analysis of the design development and perspective technology for LED lighting products," in Proc. CAID\&CD, pp. 1330-1334, Nov. 2009.

[3] M. Doshi and R. Zane, "Digital architecture for driving large LED arrays with dynamic bus voltage regulation and phase shifted PWM," in Proc. APEC, pp.287-293, Mar. 2007

[4] H. Van der Broect, G. Sauerlander, and M. Went, "Power driver topologies and control schemes for LEDs," in Proc. APEC, pp.1319-1325, Mar. 2007.
[5] S. M. Baddela and D. S. Zinger, "Parallel connected LEDs operated at high frequency to improve current sharing," in Proc. IAS, Vol. 3, pp.1677-1681, Oct. 2004.

[6] X. Wang, F. Tian, and I. Batarseh, "High efficiency parallel post regulator for wide range input dc-dc converter" IEEE Trans. Power Electron., Vol. 23, No. 2, pp. 852-858, Mar. 2008.

[7] G. Levin, "A new secondary side post regulator(SSPR) PWM controller for multiple output power supplies," Applied Power Electronics Conference and Exposition, Vol. 2, pp. 736-742, Mar. 1995.

[8] J.-H. Jung, J.-M. Choi, and J.-G. Kwon, "Design methodology for transformers including integrated and center-tapped structures for LLC resonant converters," Journal of Power Electronics, Vol. 9, No. 2, pp. 215-223, Mar. 2009.

[9] R. W. Erickson and D. Maksinmovic, Fundamentals of power electronics, 2nd ed., Kluwer Academic, pp. 705-721, 2001.

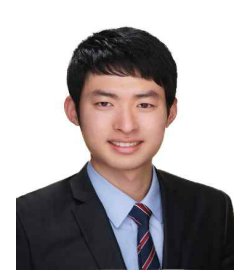

Sang-Soo Hwang received his B.S. degree in Electrical Engineering from Kookmin University, Seoul, Korea, in 2013. He is currently working toward his M.S. degree. His current research interests include lightemitting diode drivers and topologies.

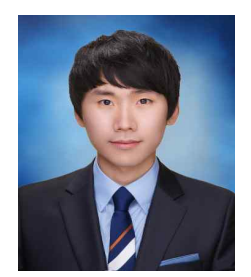

Won-Sun Hwang received his B.S. degree in Electrical Engineering from Kookmin University, Seoul, Korea, in 2013. He is currently working toward his M.S. degree. His current research interests include lightemitting diode drivers and topologies.

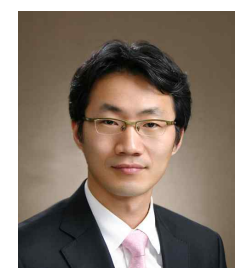

Sang-Kyoo Han received his M.S. and Ph.D. degrees in Electrical Engineering and his M.S. and Ph.D. degrees in Electrical Engineering and Computer Science from the Korea Advanced Institute of Science and Technology (KAIST), Daejeon, Korea, in 2001 and 2005, respectively. For the next six months, he was a Post-Doctoral Fellow at KAIST where he developed digital display power circuits and preformed several research activities. Since 2005, he has been with the Department of Electrical Engineering, Kookmin University, Seoul, Korea, as an Associate Professor. He has also worked for the Samsung Power Electronics Center (SPEC) and the Samsung Network Power Center (SNPC) as a Research Fellow. His current research interests include power converter topologies, LED drivers, renewable energy systems, and battery chargers for electric vehicles. Dr. Han is a Member of the Korean Institute of Power Electronics (KIPE). 